\title{
A elaboração do relatório pericial de avaliação de prática médica no âmbito do Direito Civil
}

\author{
Preparing expert reports in cases of medical \\ malpractice in Civil Law
}

\section{Lucas Pedroso Fernandes Ferreira Leal ${ }^{1}$, Élcio Rodrigues da Silva ${ }^{2}$, Viviam Paula Lucianelli Spina ${ }^{3}$, Jonas Aparecido Borracini ${ }^{4}$, Fábio Tadeu Panza ${ }^{5}$}

DOI: http://dx.doi.org/10.11606/issn.2317-2770.v23i1p27-35

\begin{abstract}
Leal LPFF, Silva ER, Spina VPL, Barracini JA, Panza FT. A elaboração do relatório pericial de avaliação de prática médica no âmbito do Direito Civil. Saúde, Ética \& Justiça. 2018;23(1):27-35.

RESUMO: No âmbito do Direito Civil, em casos que envolvem discussão sobre a assistência à saúde e se pleiteia indenização por danos, a prova pericial é essencialmente médica. O laudo técnico deve ser completo e fazer compreender a situação real do indivíduo. A função do perito é saber dar resposta ao objeto da perícia, procurando traduzir a complexidade da avaliação técnica em um conjunto de conclusões fundamentadas. É fundamental, na prática pericial, que se conheçam conceitos médico-legais bastante úteis para a elaboração de relatório médico bem circunstanciado. $\mathrm{O}$ fornecimento adequado à autoridade competente de esclarecimentos sobre o caso em tela, com base em conhecimentos científicos e sopesando-se aspectos jurídicos, é responsável pela formação do convencimento do magistrado, contribuindo para que se faça Justiça.
\end{abstract}

PALAVRAS-CHAVE: Prova Pericial; Metodologias de Avaliação de Danos; Erros Médicos; Medicina Legal; Indenização.

1.Médico Diretor do Departamento de Estudos e Perícias do Instituto de Medicina Social e de Criminologia do Estado de São Paulo (IMESC), Especialista em Medicina Legal e Perícias Médicas, Especialista em Cirurgia Geral, Doutor em Ciências pela Universidade Federal de São Paulo - UNIFESP, Pós-graduado em Medicina Legal e Perícias Médicas pela Faculdade de Ciências Médicas da Santa Casa de Misericórdia de São Paulo - FCMSCSP, Pós-Graduado em Avaliação do Dano Corporal Pós-Traumático pela Universidade de Coimbra - INML, Perito Oficial do IMESC, Presidente da Comissão Interdisciplinar de Perícias Indiretas do IMESC, Ex-Médico-Legista do Instituto Médico-Legal do Núcleo de Santos da Superintendência da Polícia Técnico-Científica.

2.Médico Diretor do Centro de Perícias do Instituto de Medicina Social e de Criminologia do Estado de São Paulo (IMESC), Especialista em Medicina Legal e Perícias Médicas, Especialista em Cardiologia, Perito Oficial do IMESC.

3.Médica Perita Oficial do Instituto de Medicina Social e de Criminologia do Estado de São Paulo (IMESC), Especialista em Medicina Legal e Perícias Médicas, Especialista em Ginecologia e Obstetrícia, Pós-graduada em Medicina Legal e Perícias Médicas pela Faculdade de Ciências Médicas da Santa Casa de Misericórdia de São Paulo, Mestre em Ciências pela Universidade Federal São Paulo.

4.Médico Diretor do Núcleo de Perícias Clínicas do Instituto de Medicina Social e de Criminologia do Estado de São Paulo (IMESC), Especialista em Medicina Legal e Perícias Médicas, Especialista em Ortopedia e Traumatologia, Perito Oficial do IMESC.

5.Médico, Especialista em Cirurgia Geral, Perito Oficial do IMESC.

Endereço para correspondência: lucaslealdr@uol.com.br 


\section{INTRODUÇÃO}

expressão coloquial "erro médico"
é bastante estigmatizada, seja pela
existência de casos específicos que têm repercussão e visibilidade na mídia, seja porque ainda não resta evidente para a população que nem todo mau resultado ou efeito adverso na Medicina esteja necessariamente ligado à inobservância de regra técnica e à inadequada assistência à saúde ${ }^{1}$. Não são raras as alegações de ocorrência de "erro médico" quando não se obtém sucesso em procedimento, diagnóstico ou terapêutico, mormente se a assistência ao doente não se dá de modo que lhe satisfaça ou quando sua evolução é desfavorável, ainda que inerente à própria condição de saúde ou à prática médica ${ }^{2}$. Entretanto, não se pode supor ter havido "erro médico" até a caracterização, pela autoridade competente, da ocorrência de "má prática médica" stricto sensu.

Conceitua-se "má prática médica" como a conduta inadequada que supõe inobservância técnica, a qual é capaz de produzir dano à vida ou agravo à saúde de outrem, mediante imperícia, imprudência ou negligência ${ }^{3}$. Neste sentido, é por meio do instituto jurídico da responsabilidade civil que se obriga o médico a ressarcir eventuais prejuízos ocasionados por má conduta 4 . Inclusive, poucos assuntos provocam mais emoção nos médicosdo que este tema ${ }^{5}$. Atualmente, inúmeros casos vêm atingindo a classe médica, especialmente quando o próprio paciente, ou seu familiar, visa se beneficiar financeiramente às custas de seu médico, sem ter a consciência da extensão danosa do ato que está cometendo 5 .

A ação cível em que se pleiteia pagamento de indenização por alegada má prática médica busca o ressarcimento dos danos causados ao paciente e/ou à sua família em consequência do reconhecimento da responsabilidade de um ou mais prestadores de serviço de saúde ${ }^{2,6}$. Omontante em dinheiro, seconcedido, geralmente leva em conta tanto o efetivo prejuízo financeiro quanto a perda não-econômica, moral, relacionada a dor e sofrimento ${ }^{7}$. A compensação financeira do indivíduo que, de fato, foi vítima de má prática médica é importante ${ }^{8}$, sendo ainda mais relevante quando utilizada para lidar com a sua saúde9. A ausência de conhecimento técnico em medicina faz com que a autoridade judicial se utilize da perícia médica, na maioria dos casos, para apuração da ocorrência e da extensão do dano alegado e para averiguar a existência de nexo de causalidade entre a conduta médica e tal dano ${ }^{1}$.

Desta forma, a perícia médica é o principal meio de prova nas ações que versam sobre má prática médica ${ }^{1}$. $\mathrm{O}$ fornecimento adequado à autoridade competente de esclarecimentos sobre a matéria em tela, com base em aprofundados conhecimentos científicos, auxilia na formação do convencimento do juízo ${ }^{1,10}$. Outros meios de prova normalmente também são utilizados, como oitiva de testemunhas e juntada de documentos, mas o laudo pericial é o precípuo subsídio que auxilia o juízo em sua decisão. Vale dizer que, uma vez restando reconhecida a responsabilidade, será fixado o quantum indenizatório.

Entrementes, tem-se que as decisões judiciais não devem separar lei e ciência, que possuem fronteiras comuns, de modo que o Poder Judiciário possa melhor fazer justiça em condições de incerteza e de ignorância ${ }^{11-}$ ${ }^{18}$, ainda que o julgador não possa se imiscuir nas apreciações de ordem técnica quanto, por exemplo, aos meios utilizados na assistência à saúde e à evolução clínica apresentada por um indivíduo, dentre outras circunstâncias, as quais são, inclusive, alvo de discussões mesmo entre profissionais especializados.

Todavia, ocorre que, em alguns casos, o laudo técnico pode não ser capaz de subsidiar a convicção judicial, deixando de fazer entender aspectos envolvidos no exercício da medicina, a natureza da doença e a complexa estrutura biopsicossocial dos indivíduos ${ }^{1}$. Assim, é imperioso que se conheçam as regras e os objetivos que regem este tipo singular de perícia, bem como se alumiem conceitos jurídicos pelo conhecimento especializado, sendo certas as implicações sobre a decisão judicial, ante o valor probante que assume em casos de alegada má prática médica.

Neste sentido, o laudo pericial deve obedecer a método harmônico e a normas específicas, no âmbito do Direito Civil, em casos em que se discute a prática médica e se pleiteia indenização pelos danos alegados. Admite-se que a atividade pericial nesta seara seja essencialmente médica, efetuada a diversos títulos, em que se aplique a lex artis. A avaliação técnica de excelência requer laudo elaborado de forma pormenorizada, após exame atento e minucioso, com interpretação de dados e conclusões fundamentadas, de maneira a esclarecer pontos controvertidos e a satisfazer categoricamente os objetivos a que se destina ${ }^{1,10}$.

Pretende-se, com o presente artigo, equacionar a elaboração do laudo técnico em casos que envolvem discussão sobre a assistência médica, mediante abordagem tanto de aspectos quanto de conceitos jurídicos e médicopericiais no âmbito do Direito Civil. Para tanto, fez-se uma revisão a respeito de temas referentes à responsabilidade civil do médico em casos de alegada má prática médica e de danos relacionados à assistência à saúde. Foi realizada pesquisa bibliográfica que incluiu as bases de dados PUBMED (National Center for Biotechnology Information, National Library of Medicine, National Institutes of Health) e SCIELO Scientific Eletronic Library Online) e livros-texto de Direito, de Medicina Legal e de Avaliação do Dano Corporal Pós-Traumático. 


\section{DESENVOLVIMENTO}

A "má prática médica" tem sido objeto de debate público nas últimas décadas ${ }^{19} \mathrm{e}$ o interesse na mortalidade que lhe é atribuída não é recente ${ }^{20}$. O médico muitas vezes não figura só como réu no contencioso cível, apesar das ações propostas alegarem "erro médico". Hospitais, clínicas, laboratórios, operadoras de saúde e poder público, dentro dos limites da atividade prática médica, respondem a ações indenizatórias nesta seara, por serem também considerados responsáveis pelos serviços de saúde prestados.

Entende-se por "má prática médica" a falha no exercício da profissão da qual advém um mau resultado ou um resultado adverso, efetivando-se por meio da ação ou da omissão do profissional ${ }^{2,21}$. Quando da ação ou da omissão advém um dano, que ocorreu por culpa comprovada, havendo claro e indiscutível nexo de causalidade entre o ato médico e o dano, o profissional é responsabilizado ${ }^{2,21,22}$. A avaliação pericial da suposta "má prática médica" é a mais complexa e delicada tarefa da legisperícia ${ }^{21}$.

Mesmo com os avanços da ciência e com a crescente incorporação de novas tecnologias, a Medicina ainda não permite que se evitem algumas situações adversas $^{1}$. A ocorrência de um dano, de uma complicação, de uma intercorrência, ou mesmo o tratamento médico que não apresente bons resultados ou que não corresponda à expectativa do paciente ou de seus familiares, pode levar à dúvida se o insucesso foi apenas um mau resultado ou se decorre de um "erro médico"2,23. Fatores inerentes a cuidados operacionais envolvidos na prestada assistência à saúde dos indivíduos, dentre outros, e muito além da prática médica per se, aliados à relação médico-paciente deteriorada, são responsáveis por grande parte das denúncias feitas na Justiça Comum ${ }^{3,5,20,24-26}$.

Eventos adversos ocorrememproporção entre 2,9\% a 3,7\% das internações hospitalares nos Estados Unidos da América; destes, de 27,4\% a 32,6\% são caracterizados como resultantes de má prática médica ${ }^{27}$. Atribui-se aos "erros médicos" a oitava causa de óbito naquele país ${ }^{20}$, onde um a cada seis profissionais é citado numa ação judicial ${ }^{7,21}$. Num estudo realizado com dados de $1^{\circ}$ de janeiro de 1985 a 31 de dezembro de 2005, observouse que $66 \%$ dos médicos envolvidos em ações judiciais já havia se envolvido em questionamentos anteriores ${ }^{28}$. Dados publicados pelo Instituto de Medicina, órgão da respectiva Academia Nacional de Ciências, revelaram que o número de mortes por "má prática médica" pode chegar a 98 mil por ano, e que o prejuízo financeiro secundário se dá em torno de 17 a 29 bilhões de dólares anuais, no que tange a efeitos adversos preveníveis ${ }^{29}$. Na Alemanha, ortopedia e cirurgia geral estão envolvidasem em mais de $50 \%$ das ações judiciais ${ }^{30}$. No México, a "má prática médica"foi caracterizada em mais da metade dos pareceres da Comissão Nacional de Arbitragem Médica, entre os anos de 1996 e $2000^{20}$.

Atualmente, no Brasil, apesar de não existirem dados específicos sobre o assunto, a literatura indica aumento das demandas jurídicas impetradas por pacientes contra seus médicos ${ }^{24,26,31}$. As denúncias contra esses profissionais no Estado de São Paulo, do mesmo modo, têm crescido progressivamente com o passar dos $\operatorname{anos}^{3,32}$. Dentre as mais de 3.000 denúncias anuais recebidas pelo CREMESP, cerca de $25 \%$ envolvem atos médicos supostamente caracterizados como imperícia, imprudência e negligência do profissional e que teriam causado potencial prejuízo à saúde e à vida do paciente ${ }^{3}$. Tem-se que a especialidade de cirurgia geral assume o terceiro lugar em relação às demandas ajuizadas contra os médicos, empatada com ortopedia e traumatologia, nas ações referentes à alegada má prática médica ${ }^{3,24}$.

Em razão de inúmeros fatores, constata-se que, mesmo em casos aparentemente semelhantes, há decisões judiciais diversas, reformadas ou não nas instâncias superiores $^{33-39}$. Por isto, não há consenso jurisprudencial em relação a diversos pontos do tema ${ }^{31,33,34}$. É mister que o médico perito tenha conhecimento de conceitos úteis para a elaboração de um laudo pericial em um caso que verse sobre "má prática médica".

Neste sentido, é necessário dizer que o médico, em geral, possui uma relação contratual que envolve uma obrigação de meio com seu paciente ${ }^{22}$. Significa dizer que, na prática assistencial, via de regra, há comprometimento com todo o empenho profissional e uso de materiais, técnicas, ciência e demais recursos necessários, sem, contudo, compromisso de resultado. Isto é, há obrigação de se realizar uma determinada atividade, com zelo e adequação, sem a necessária obrigação de atingir uma meta, a qual não pode ser garantida, no sentido de salvar ou curar o paciente. Consideradas tais premissas, na seara jurídica, a existência de conduta irregular culposa do médico faz nascer o dever de indenizar o paciente que sofreu um dano, havendo a necessidade da presença de uma relação causa-efeito no proceder do profissional médico $^{31,34}$

Esta obrigação a que estão sujeitos os médicos, no exercício profissional, é, em regra, subjetiva ${ }^{22}$, baseada no princípio da 'culpa' stricto sensu e, para ser caracterizada, há necessidade de que existam três elementos $7,21,22,34$ : (1) ação ou omissão - conduta culposa / ato lesante, a qual promova um (2) dano ou prejuízo ao indivíduo, e uma relação estabelecida entre o agente que dá causa ao dano, culposamente, sem os cuidados necessários, sem precaução, sem buscar evitá-lo - (3) nexo causal.

Contudo, há casos em que, em razão de determinadas condicionantes jurídicas, a responsabilidade seja enquadrada como objetiva. Basicamente, esta responsabilidade tem na teoria do risco da atividade sua viga mestra, onde o conceito de culpa fica diluído. Assim, 
basta a demonstração do nexo de causalidade entre o ato e o dano para que se obrigue a repará-lo com a indenização, prescindindo a prova da culpa $a^{2,21,22,34}$.

A responsabilidade médica subjetiva é perquirida através da presença de conduta culposa em seus atos, no agir ou no não-agir, a qual não é presumida, devendo ser comprovada $^{2}$. Cabe ressaltar que não é necessário que a culpa do médico seja grave para que seja civilmente responsabilizado, uma vez existindo o dano e estabelecido o nexo causal ${ }^{22}$. Há três modalidades bem caracterizadas de culpa que podem ocorrer no exercício da medicina:

- Imperícia: falta de aptidão especial, habilidade ou experiência, ou de previsão, no exercício de determinada função, profissão, arte ou ofício; designa o inábil, o desqualificado, o que não possui conhecimento técnico ou científico para a prática de determinados atos ou procedimentos de natureza médica; corresponde a um despreparo teórico e/ou prático por insuficiência de conhecimento, incapacidade ou inabilitação para exercer o ofício pela ausência de conhecimentos elementares ${ }^{2,21,40}$.

- Imprudência: falta involuntária de atenção ordinária e de observação de medidas de precaução e segurança de consequências previsíveis, que se fariam necessárias, no momento, para evitar um mal, perigo ou insucesso, ou a prática de certa infração; como conduta ativa, é a prática de um ato perigoso; é a tomada de uma atitude precipitada e sem a cautela necessária; audácia, intempestividade, precipitação ou desconsideração; caráter comissivo $^{2,21,40}$.

- Negligência: omissão voluntária de diligência ou cuidado, falta ou demora no prevenir ou obstar um dano; inoportunidade na aplicação de meios mais aptos, que a prudência e o bom senso aconselham, em circunstâncias tais, de consequências previsíveis; como conduta passiva, é a desatenção, o descuido, a inércia, a falta de interesse; quando não se oferecem os cuidados necessários, sugerindo inação ou passividade; ato omissivo $^{2,21,40}$

O ‘dano’, prejuízo ressarcível experimentado pelo lesado, é tido em nosso meio como a lesão, a diminuição ou a destruição que, devido a um certo evento, sofre uma pessoa, contra sua vontade, em qualquer bem - concreto ou abstrato - ou interesse jurídico ${ }^{22}$. Assim, na avaliação do dano, por exemplo, tanto qualitativa quanto quantitativa, considera-se a alteração anatômica ou funcional de uma estrutura, assim como qualquer desordem da normalidade individual ou suas consequências na vida em sociedade, de modo individualizado, em que os padrões médicolegais utilizados na perícia variam de acordo com a natureza da análise técnica ${ }^{10,21}$. A identificação do dano está relacionada com o diagnóstico, que é firmado com base em princípios propedêuticos consagrados, tendo sua valorização que ser apurada de acordo com rigoroso método científico.
A relação entre o ato médico e o dano verificado deve ser estabelecida pelo perito, determinando-se o nexo de causalidade de forma clara. A conduta culposa será configurada ou não posteriormente. Outrossim, independentemente da discriminação, no caso concreto, de uma ou mais das três modalidades de culpa, mediante interpretação judicial das evidências, não há qualquer implicação sobre o grau da condenação ${ }^{6,22,34}$. Compete ao perito fornecer ao juízo os elementos que permitam caracterizar os pressupostos necessários à configuração da responsabilidade civil ${ }^{22}$. Ressalte-se que o perito não define se existe ou não culpa, nem se manifesta sobre o mérito $^{2}$, mas fornece subsídios ao magistrado e esclarece a conduta - omissiva ou comissiva - que deu origem aos danos sobre os quais versa a lide.

Tem-se que a medicina evoluiu mais durante as últimas cinco décadas do que em toda a história. $\mathrm{O}$ desenvolvimento de novas técnicas de diagnóstico e de tratamento, o aperfeiçoamento da atenção multiprofissional, a tecnologia, dentre outros, vem tornando a arte médica muito mais complexa e bemsucedida $^{41}$. Contudo, há indivíduos mais debilitados portadores de afecções graves ou de mau prognóstico -, que são submetidos a intervenções variadas com fins terapêuticos, não obstante a possibilidade de haver complicações ou de se ter desfecho desfavorável que ainda perdure. É de se ressaltar que tais riscos não são insignificantes, especialmentes nessa população, ainda que se busque salvaguardar os interesses do paciente, mesmo com todo o avanço da Medicina na qualidade da assistência à saúde.

Significa dizer que o tratamento médico não é isento de risco $^{23}$. Qualquer procedimento cirúrgico, por exemplo, é dotado de riscos ${ }^{20}$, em graus variáveis, que podem ser de mortalidade e/ou de morbidade, inerentes ao procedimento anestésico-operatório, à doença que se busca tratar e/ou à resposta do organismo do próprio indivíduo. Diversos tipos de complicações e intercorrências podem ocorrer, assim como ser o desfecho desfavorável, independentemente do preparo do profissional ou da possibilidade de previsibilidade que possa ter o médico ${ }^{2,23}$, considerando-se, também, a complexa estrutura biopsicossocial de um paciente ${ }^{24}$, a natureza de sua afecção de saúde, a existência de situações anômalas, e até mesmo a influência do meio de onde provém o indivíduo ${ }^{2,9,42}$. A própria prevenção pode comportar riscos tanto ou mais graves do que aquele que se quer evitar ou, ainda, trazer dificuldades para o procedimento cirúrgico, propiciando maior risco para o êxito final daquele ${ }^{2,21}$. Deve o médico informar, com transparência, o paciente e seus familiares a respeito dos riscos existentes, além de fornecer orientações e esclarecimentos de costume, de modo que aquele possa, de forma autônoma, após a discussão, decidir por se submeter ou não ao tratamento médico oferecido ${ }^{21,23,26}$. 
Há de se diferenciar, portanto, a evolução natural de um estado mórbido de um indivíduo, de um desfecho não exitoso advindo da evolução de uma moléstia, de condições orgânicas existentes, e/ou pela própria limitação da arte médica, de uma eventual falha na assistência à saúde. Daí a importância dos itens "descrição" e "discussão" de um relatório médico pericial ${ }^{10}$. O Professor França $(2008)^{21}$ oferece alguns conceitos que merecem destaque: aponta que Mau Resultado é o insucesso advindo pela própria resposta orgânica do paciente, pela evolução desfavorável natural do quadro, pelas limitações da medicina, e independente dos cuidados médicos; Mal Incontrolável é o decorrente de uma situação grave, insolúvel, de curso inexorável; Acidente Imprevisível é o resultado lesivo oriundo de caso fortuito ou força maior, durante ou em face de um ato médico, atípico, de mínima frequência, imprevisto e inevitável; Intercorrência é um evento superveniente variável que ocorre de permeio à evolução natural de uma doença ou de seu tratamento, típico, secundário a fatores diversos, ainda que se tenha precaução; e Complicação é um novo fenômeno mórbido que se dá no curso de determinada enfermidade ou de seu tratamento, típico, dependente das peculiaridades de cada caso, ainda que haja prevenção. Tais situações não são infrequentes e podem ocorrer de modo inevitável, apesar de todos os cuidados e medidas profiláticas, ainda que sejam conhecidas no meio médico, e devem ser cuidadosamente explicadas ao juízo.

Note-se que deslizes cometidos por profissionais de outras áreas podem não acarretar maiores conseqüências $^{24}$, mas podem, de igual maneira, provocar resultados indesejados e, muitas vezes, sequelas irreversíveis ao paciente, sem ser o caso de um "erro médico". É frequente, na mídia, a atribuição de falhas de enfermagem ou falta de recursos hospitalares para o devido atendimento a um médico assistente ${ }^{1}$. Por isso, a noção de outros conceitos jurídicos também é de fundamental interesse numa perícia médica, contribuindo para determinar a autoria de cada conduta e esclarecendo o que pode ser imputado a cada agente.

Tudo o que for destacável do ato médico, dito Ato Destacável, engaja a responsabilidade de quem o praticou ${ }^{21,22}$. Isola-se, com isso, a atuação de outrem, permanecendo a responsabilidade do agente que executou determinado ato. A Responsabilidade Derivada ou Convergente, considerando-se a divisão e a execução de determinadas tarefas, na área da saúde, no tempo presente, por profissionais não-médicos, engloba o conceito da solidariedade profissional, cuja responsabilidade é compartida entre os membros de uma equipe multiprofissional, assistencial e/ou hospitalar; tem-se divisão da responsabilidade entre todos, de acordo com a graduação hierárquica e a capacidade de cada componente em influenciar, de maneira marcante, no desfecho ${ }^{21}$. A incorporação à nova realidade de assistência à saúde de enfermeiros, bioquímicos, dentre outros, de forma quase que independente, por suas obrigações, não os destitui de sua responsabilidade. Não se pode olvidar, ainda, da Responsabilidade do Paciente e de Terceiros, no sentido de descumprimento às recomendações médicas sobre cuidados necessários, uso de medicações e realização de procedimentos, pelo próprio paciente ou seu responsável ${ }^{22,34}$.

Os objetivos essenciais da perícia médica em casos em que se discute a assistência prestada à saúde, no âmbito do Direito Civil, resumem-se em:

- estudar o nexo causal, determinando o elo entre ato médico e o dano verificado, ou referir sua ausência;

- considerar o dano, que deve ser concreto, qualificado e quantificado;

- avaliar o ato médico e as circunstâncias em que se deu, em relação à lex artis, meios, condições, tratamento e necessidades individuais.

O estabelecimento, ou não, do nexo de causalidade é primordial e de competência pericial. A relação entre o ato e o dano consequente é necessária para que se atribua responsabilidade ao médico; ou seja, o dano deve estar encadeado com a causa lesante ${ }^{22}$. A análise criteriosa da existência, ou não, desse vínculo entre uma falta e um prejuízo causado auxilia no pronunciamento do juízo sobre a matéria médica sub judice, por ser pressuposto da responsabilidade civil. Na maioria dos casos, a natureza do pleito não reside na qualidade nem na quantidade da lesão, mas essencialmente nas condições em que se deu a relação entre o evento e resultado ${ }^{21}$. Em verdade, para a caracterização da responsabilidade civil do médico é imprescindível o estabelecimento do nexo de causalidade entre os efeitos de seus atos ou omissões e os danos alegados pelos autores. Eis que não basta simplesmente alegar o suposto "erro médico"; é fundamental que se demonstre, de forma clara e objetiva, não só o dano, mas principalmente o nexo de causalidade entre a conduta do réu e o que foi verificado na perícia médica ${ }^{1}$.

O dano é o elemento nuclear da responsabilidade civil atribuída ao médico ${ }^{21,22,34,40}$, imprescindível de ser avaliado. A ausência de prejuízo ou agravo à saúde de outrem, ainda que a conduta seja grave, não gera a obrigação de ressarcir; não se atribui culpa, nem se fixa indenização, sem a experiência do dano ${ }^{22,34}$. A perícia se debruça sobre o padrão e a extensão do dano, fato objetivo, certo, cabalmente demonstrado e comprovado, de modo a auxiliar o juiz na apuração da responsabilidade do profissional e na fixação da indenização. Juridicamente, havendo lesão ao corpo ou a aspectos patrimoniais concretos ou abstratos (morais), há o dever de indenizar o prejuízo causado a outrém ${ }^{22,34}$. $\mathrm{Na}$ prática médicopericial, faz-se necessária uma abordagem mais rigorosa e integral na avaliação do dano pessoal. Há que se fornecer 
subsídios para se caracterizar o dano, ainda, como mau resultado, complicação possível, dentre outros, como expusemos, ou mesmo como consequência à falha da assistência à saúde.

O seguimento de um padrão aceito de cuidados médicos, consagrado na literatura, é uma necessidade ${ }^{43}$. Contudo, na análise pericial, deve-se verificar que um padrão de conduta médica pode variar dentro de certos limites ${ }^{44}$. As diretrizes médicas são recomendações no sentido de se orientar o diagnóstico e a terapêutica, de acordo com o conhecimento da ciência atual, que devem ser aplicadas de acordo com as particularidades de cada caso, sem constituir uma norma, uma determinação, um protocolo que deva ser invariavelmente seguido. $\mathrm{Na}$ avaliação pericial, o atendimento prestado deve ser considerado como um todo e verifica-se, sob a óptica médico-legal, objetivamente, se houve violação da bona praxis e se qualquer dano ocorreu como consequência ${ }^{45}$. O contexto clínico, os procedimentos adotados, o grau em que o desfecho corresponde com o resultado previsto, as condições organizacionais, as circunstâncias envolvidas, além dos aspectos científicos, devem ser considerados ${ }^{46}$, uma vez que os componentes importantes da prática médica segura incluem: proficiência, trabalho em equipe, baseado na arte contemporânea, e adequada infraestrutura dos serviços de saúde, com contínuo aprimoramento profissional de funcionários ${ }^{47}$.

É fundamental esclarecer ao juízo o risco a correr pelo indivíduo, nas condições em que se encontrava à época dos fatos, assim como a devida informação se é o caso de complicação, intercorrência, acidente imprevisível, mau resultado ou mal incontrolável, o que deve ser analisado com extremo rigor pelo perito. Sabe-se que todo procedimento técnico, mesmo que corretamente efetuado, traz em si a possibilidade de resposta adversa, intrínseca às limitações da medicina e da natureza humana. Ainda, é de se ponderar a pertinência de intervenção e a necessidade de se enfrentar o risco. Eventualidades existentes ou supervenientes, modificando o curso natural do resultado, dentre outros fatores, devem ser discriminados.

Há de se considerar toda uma constelação de fatores, em complexa interação, que envolve o restabelecimento da saúde: fatores endógenos, psicológicos, próprios da doença, dentre os mais variados, podem contribuir para um evento indesejado, independentemente das medidas usuais e dos meios empregados, de acordo com a particularidade de cada indivíduo. Com efeito, não se pode atribuir culpa ao profissional se as consequências dos cuidados ou do tratamento por ele prescritos fogem de seu total controle, a depender da resposta e do funcionamento de cada organismo, o que é muito particular e está além dos conhecimentos e do alcance da mente humana. Ademais, a imperfeição da ciência é uma realidade com a qual se convive ${ }^{1}$.
De fato, há dificuldade para o leigo em medicina apurar a existência de elementos que possam configurar a má prática médica, pela complexidade técnica envolvida em determinadas situações ${ }^{1}$. É notória a influência de aspectos relacionados às condições de saúde do indivíduo envolvido, do ambiente, da situação, dos riscos inerentes a qualquer ato médico, e da evolução da própria afecção de saúde na recuperação de alguma medida intervencionista, com fins terapêuticos, por exemplo. $\mathrm{O}$ reconhecimento da efetiva relação entre a conduta do profissional e o dano alegado, às vezes inevitável ou inexistente, é de competência pericial.

$\mathrm{Na}$ ótica jurídica, normalmente o médico age com culpa não por ter errado o diagnóstico, mas por ter intervindo e insistido em uma conduta errada, inadequada, sem benefícios ou resultados positivos para seu paciente, por conta da qual não poderá este último apresentar melhora ou cura de sua afecção. Há, contudo, casos em que já se reconheceu a existência de responsabilidade por erro diagnóstico. De qualquer forma, não se há de imputar responsabilidade indenizatória ao médico em face de um insucesso, se não restar evidenciada sua conduta culposa, atípica, irregular ou inadequada, uma vez que o compromisso assumido constitui obrigação de meio e não de resultado. Observadas as regras da ciência médica à época dos fatos e atendidos todos os cuidados habituais, não há como se responsabilizar o médico por culpa em nenhuma de suas modalidades, já que nenhuma falta lhe pode ser imputada. Diante da falta de requisitos para se caracterizar a má prática, não se impõe qualquer responsabilização; ausente a comprovação de ato culposo ou dano secundário, afasta-se a pretensão indenizatória.

Não incumbe ao perito decidir pela presença, ou não, de conduta culposa, elemento do ato ilícito. Todavia, além do estudo da relação de causalidade, deve esclarecer o juízo quanto à adequação ou não da conduta, fornecendolhe elementos para que determine a existência ou não de culpa; discorrer sobre a ocorrência de caso fortuito ou por força maior, impossível de ser evitado ou impedido; registrar que o dano inexiste, ocorreu por outros fatores ou ato de terceiros, ou é secundário às respostas orgânicas do paciente ou ao não cumprimento de recomendações médicas. Uma vez estabelecido o nexo de causalidade e caracterizado o dano, julgando-se a conduta culposa, tendo-se configurado a mala práxis, há condenação do médico ${ }^{1}$.

A prestação de serviços de saúde se dá de forma complexa, de modo geral sem compromisso de resultado, envolvendo, muitas vezes, vários médicos, de especialidades distintas, e outros profissionais da área. Devido às peculiaridades do trabalho médico, as noções de "ato destacável" e de "responsabilidade derivada", pelo ordenamento jurídico, devem ser consideradas. Impende isolar a atuação de outrem no caso. Isso porque a presença de culpa, no proceder do profissional médico, será objeto 
de avaliação judicial, fazendo, ou não, nascer daí o dever de indenizar o paciente que sofreu determinado prejuízo, real e efetivo, com o nexo causal estabelecido.

$\mathrm{Na}$ literatura, há quem defenda que a revisão de prontuários médicos é tendenciosa quando a ocorrência de um dano é grave, considerando-se, nestes casos, os cuidados prestados como insuficientes ${ }^{19}$. A análise de especialistas teria, assim, viés de retrospecto e de resultado. Viés de Retrospecto se relaciona com a probabilidade de um evento adverso ser percebido e/ ou evitado pelo observador naquela situação. Viés de Resultado é uma distorção subconsciente da interpretação, produzida pelo conhecimento prévio do resultado adverso pelo observador. Há evidências que, quando um perito verifica que houve um resultado adverso, uma lesão grave ou uma deficiência, critica retrospectivamente as decisões do médico-assistente ${ }^{19}$. Daí a necessidade de o perito, após a leitura dos autos, da documentação médico-legal apresentada, da análise dos resultados de exames complementares disponibilizados, considerando-se, fundamentalmente, os achados do exame clínico pericial, à luz dos conhecimentos médicos, estabelecer um diagnóstico. É importante que o experto avalie cronologicamente a evolução do caso concreto, a pertinência das condutas, sem se ater, desde o princípio ao evento final desfavorável que já é de seu conhecimento. A noção sobre o efeito desses viéses deve ser conhecida também por membros do judiciário ${ }^{19}$, não se admitindo conceitos pré-estabelecidos na análise pericial de condutas médicas, o que pode levar a conclusões viciosas, e mesmo decisões injustas ${ }^{48,49}$.

Cabe mencionar que pode vir a se imaginar que haja, neste tipo de processo indenizatório, o esprit de corps ou corporativismo, por se tratar de avaliação de conduta de um ou mais colegas de profissão. Não se pode jamais dizer que isto seja a regra e, de igual maneira, que seja inverídico dizer que um certo favorecimento não ocorra $^{2}$, lamentavelmente, merecendo registro que às vezes encontram-se laudos bastante severos, apontando claramente e com veemência condutas atípicas de seus colegas, ora esdrúxulas e abomináveis ${ }^{1}$, deixando o juízo se aperceber do que se sucedeu, diante de tudo o que foi exposto e discutido.

A sentença é uma peça de inteligência que se baseia em todas as provas pertinentes apresentadas e no previsto pelas doutrina, legislação e jurisprudência, conforme a convicção do magistrado ${ }^{1}$. Sabe-se que a opinião do perito não vincula a do juiz. A autoridade judicial não fica adstrita ao laudo médico, podendo discordar, no todo ou em parte, das suas conclusões, e determinar a realização de nova perícia, se assim julgar conveniente. Pode haver casos, embora mais raros, em que o juiz, analisando a perícia junto às demais provas constantes do processo, decida em sentido oposto ao laudo pericial; assim prevê a legislação ${ }^{21,22,34,35,40}$. A prova técnica de natureza médica só é útil ao fornecer os subsídios necessários para que autoridade estenda seu olhar, com base científica, sobre o caso concreto. $\mathrm{O}$ julgamento justo, sem separar a lei e a ciência, finda quando resta evidenciado ter havido má prática médica, ou não, do modo devido ${ }^{1}$.

\section{CONSIDERAÇÕES FINAIS}

A abordagem pericial da assistência prestada à saúde dá-se a partir de conceitos jurídicos, os quais devem ser aclarados pelo conhecimento especializado. $\mathrm{Na}$ elaboração do laudo técnico em um processo que verse sobre a responsabilidade civil do médico, é incumbência do perito explorar três elementos essenciais: ato médico, dano e nexo causal. Ademais, compete ao experto fornecer ao juízo subsídios que permitam verificar a presença, ou não, de culpa na conduta do profissional, meritoriamente, ante as circunstâncias da prática médica em tela. O laudo médico-legal deve fornecer os esclarecimentos que requerem conhecimento médico científico, com vistas a fornecer subsídios essenciais para a decisão judicial.

Leal LPFF, Silva ER, Spina VPL, Barracini JA, Panza FT. Preparing expert reports in cases of medical malpractice in Civil Law. Saúde, Ética \& Justiça. 2018;23(1):27-35.

ABSTRACT: In civil law, cases involving claims on health care and compensation for damages require a thorough medical report. Medical experts must comply with the legal proceedings, especially in medical malpractice litigation. In the assessment of personal injuries, the physician must respond to the object of litigation, translating the complexity of the technical evaluation into a set of evidence-based conclusions. Experts must have thorough knowledge of medico-legal concepts to produce clear and objective reports. Since the medical report strongly influences the magistrate's decisions, providing adequate opinion on the case, based on scientific knowledge and acknowledging judicial factors is an important activity that contributes to justice.

KEY WORDS: Expert Testimony; Damage Assessment Methodologies; Medical Errors; Forensic Medicine; Compensation and Redress. 


\section{REFERÊNCIAS}

1. Leal LPFF, Milagres A. A importância do laudo pericial médico na formação do entendimento do juízo: análise de casos de suposta má prática médica em cirurgia geral. Saúde, Ética \& Justiça. 2012;17(2):82-90. DOI: http:// dx.doi.org/10.11606/issn.2317-2770.v17i2p82-90

2. Giostri HT. Erro médico à luz da jurisprudência comentada. $2^{\mathrm{a}}$ ed. Curitiba: Juruá; 2008.

3. Conselho Regional de Medicina do Estado de São Paulo (CREMESP). O médico e a justiça: um estudo sobre ações judiciais relacionadas ao exercício profissional da medicina. São Paulo: CREMESP; 2006.

4. Boyaciyan K, Camano L. O perfil dos médicos denunciados que exercem ginecologia e obstetrícia no estado de São Paulo. Rev Assoc Med Bras. 2006;52(3):144-7. DOI: http:// dx.doi.org/10.1590/S0104-42302006000300013

5. Dove JT, Brush JE Jr, Chazal RA, Oetgen WJ. Medical professional liability and health care system reform. J Am Coll Cardiol. 2010;55(25):2801-3. DOI: http://dx.doi. org/10.1016/j.jacc.2010.03.028

6. Souza NTC. Responsabilidade civil e penal do médico. Campinas: LZN Editora; 2003.

7. Bal BS. The expert witness in medical malpractice litigation. Clin Orthop Relat Res. 2009;467(2):383-91. DOI: http:// dx.doi.org/10.1007/s11999-008-0634-4

8. Davis P, Lay-Yee R, Fitzjohn J, Hider P, Briant R, Schug S. Compensation for medical injury in New Zealand: does "'no-fault" increase the level of claims making and reduce social and clinical selectivity? J Health Polit Policy Law. 2002;27(5):833-54.

9. Wood C. The misplace of litigation in medical practice. Aust N Z J Obstet Gynaecol. 1998;38(4):365-76.

10. Magalhães T, Corte-Real F, Vieira DN. O relatório pericial de avaliação do dano corporal em Direito Civil. In: Vieira DN, Quintero JA, coords. Aspectos práticos da avaliação do dano corporal em Direito Civil. Brasília: Caixa Seguros e Imprensa da Universidade de Coimbra; 2008.

11. Jasanoff S. Law's knowledge: science for justice in legal settings. Am J Public Health. 2005;95 Suppl 1:S49-58.

12. Feld AD, Carey WD. Expert witness malfeasance: how should specialty societies respond? Am J Gastroenterol. 2005;100(5):991-5.

13. Ryan M. The adversarial court system and the expert medical witness: 'The truth the whole truth and nothing but the truth? Emerg Med (Fremantle). 2003;15(3):283-8.

14. Kaufman HH. The expert witness. Neither Frye nor Daubert solved the problem: what can be done? Sci Justice. 2001;41(1):7-20. DOI: http://dx.doi.org/10.1016/S13550306(01)71844-8

15. Becker W, Laufs A, Schreiber HL. The function and legal position of the medical expert. Laryngol Rhinol Otol (Stuttg). 1977;56(9):723-40.

16. Hawkins TS. Expert testimony: a perspective from the trenches. J Am Coll Radiol. 2005;2(2):126-30. DOI: http:// dx.doi.org/10.1016/j.jacr.2004.06.003

17. Ulsenheimer K. Quality assurance by experts. Zentralbl Gynakol. 1998;120(12):588-92.

18. Specht G. Conflicting expert opinions from the medical viewpoint. Z Arztl Fortbild (Jena). 1996;90(7):640-1.

19. Hugh TB, Dekker SW. Hindsight bias and outcome bias in the social construction of medical negligence: a review. J Law Med. 2009;16(5):846-57.

20. Arenas-Márquez H, Anaya-Prado R. Errors in surgery. Strategies to improve surgical safety. Cir Cir. 2008;76(4):355-61

21. França GV. Medicina legal. $8^{\text {a }}$ ed. Rio de Janeiro: Guanabara-Koogan; 2008.

22. DinizMH. Curso de direito civil brasileiro. Responsabilidade civil. Vol 7. 19ª ed. São Paulo: ERT; 2005.

23. Ferraz EM. Complicação ou erro médico? Rev Col Bras Cir. 2006;33(4):205-6. DOI: http://dx.doi.org/10.1590/ S0100-69912006000400001

24. Bitencourt AVG, Neves NMBC, Neves FBCS, ISPS Brasil, LSC Santos. Análise do erro médico em processos éticoprofissionais: implicações na educação médica. Rev Bras Educ Med. 2007;31(3):223-8.

25. Edwards IR. The WHO world alliance for patient safety: a new challenge or an old one neglected? Drug Saf. 2005;28(5):379-86. DOI: http://dx.doi. org/10.2165/00002018-200528050-00002

26. Godinho AM, Lanziotti LH, Morais BS. Informed consent: the understanding of lawyers and courts. Rev Bras Anestesiol. 2010;60(2):207-14. DOI: http://dx.doi. org/10.1590/S0034-70942010000200014

27. Griffen FD, Stephens LS, Alexander JB, Bailey HR, Maizel SE, Sutton BH, et al. Violations of behavioral practices revealed in closed claims reviews. Ann Surg. 2008;248(3):468-74. DOI: http://dx.doi.org/10.1097/ SLA.0b013e318185e196

28. Conklin LS, Bernstein C, Bartholomew L, Oliva-Hemker M. Medical malpractice in gastroenterology. Clin Gastroenterol Hepatol. 2008;6(6):677-81. DOI: http:// dx.doi.org/10.1016/j.cgh.2008.02.047

29. Kohn LT, Corrigan JM, Donaldson MS, eds. To error is human: building a safer health system. Washington: National Academy Press; 2000.

30. Hildebrand B, Küther SS, Dreher I. Expert assessment of medical treatment errors--a new responsibility for the medical service of health insurance. Gesundheitswesen. 1999;61(1):8-12.

31. Souza NTC. Responsabilidade civil no erro médico [Internet]. Porto Alegre; 2001. Disponível em: http://egov. ufsc.br/portal/sites/default/files/anexos/9158-9157-1-PB. pdf

32. Conselho Regional de Medicina do Estado De São Paulo (CREMESP). Ética em ginecologia e obstetrícia. $3^{\text {a }}$ ed. São Paulo: CREMESP; 2004.

33. Deutsch E. Medical expert assessment in the AngloAmerican lawsuit. Z Arztl Fortbild (Jena).1996;90(7):64852.

34. Gonçalves CR. Responsabilidade civil. $11^{\text {a }}$ ed. São Paulo: Saraiva; 2009

35. Breda J. Responsabilidade civil do médico. $2^{\mathrm{a}}$ ed. São Paulo: Brasbiblos; 1997.

36. B-Lynch C, Coker A, Dua JA. A clinical analysis of 500 medico-legal claims evaluating the causes and assessing the potential benefit of alternative dispute resolution. $\mathrm{Br} \mathrm{J}$ Obstet Gynaecol. 1996;103(12):1236-42.

37. Schwab S, Streuli R. Extrajudicial expert assessment--what 
is the basis for complaints against internists?. Praxis (Bern 1994). 1999;88(48):1981-93.

38. Studdert DM, Mello MM, Gawande AA, Gandhi TK, Kachalia A, Yoon C, et al. Claims, errors, and compensation payments in medical malpractice litigation. N Engl J Med. 2006;354(19):2024-33. DOI: http://dx.doi.org/10.1056/ NEJMsa054479

39. Traina F. Medical malpractice: the experience in Italy. Clin Orthop Relat Res. 2009;467(2):434-42. DOI: http://dx.doi. org/10.1007/s11999-008-0582-z

40. Kfouri Neto M. Responsabilidade civil do médico. $3^{\text {a }}$ ed. São Paulo: Ed. Revista de Tribunais; 1999.

41. Carstensen G. Medical malpractice from the physician's viewpoint. Z Arztl Fortbild (Jena). 1995;89(6):570-5.

42. Griffen FD, Turnage RH. Reviews of liability claims against surgeons: what have they revealed? Adv Surg. 2009;43:199209.

43. Schreiber HL. The standard of required medical responsibility as an instrument in malpractice cases. Versicherungsmedizin. 1995;47(1):3-5.

44. Ulsenheimer K. Expert evidence. General prerequisites and procedural characteristics for expert opinions. Anaesthesist. 2005;54(11):1081-8. DOI: http://dx.doi.org/10.1007/ s00101-005-0934-y

45. Hammond CB, Schwartz PA. Ethical issues related to medical expert testimony. Obstet Gynecol. 2005;106(5 Pt 1):1055-8. DOI: http://dx.doi.org/10.1097/01. AOG.0000182587.83516.76

46. Giard RW, Stolker CJ. The physician as an expert in medical negligence cases. Ned Tijdschr Geneeskd. 2003;147(17):819-23.

47. Cuschieri A. Nature of human error: implications for surgical practice. Ann Surg. 2006;244(5):642-8. DOI: http://dx.doi.org/10.1097/01.sla.0000243601.36582.18

48. Crosby E. Medical malpractice and anesthesiology: literature review and role of the expert witness. Can J Anaesth. 2007;54(3):227-41. DOI: http://dx.doi. org/10.1007/BF03022645

49. Weir SS, Curtis P, McNutt RA. Expert testimony based on decision analysis: a malpractice case report. J Gen Intern Med. 1990;5(5):406-9.

Recebido para publicação: 05/05/2018

Aceito para publicação: 10/07/2018 